\title{
Transmating: conjugative transfer of a new broad host range expression vector to various Bacillus species using a single protocol
}

Simon Heinze ${ }^{1}$, Petra Kornberger ${ }^{1 *}$ (D), Christian Grätz ${ }^{1}$, Wolfgang H. Schwarz ${ }^{1}$, Vladimir V. Zverlov ${ }^{1,2}$ and Wolfgang Liebl ${ }^{1}$

\begin{abstract}
Background: The genus Bacillus includes a great variety of species with potential applications in biotechnology. While species such as B. subtilis or B. licheniformis are well-known and used to provide various products at industrial scale, other Bacillus species are less characterized and are not yet used in commercial processes. One reason for this is the fact that genetic manipulation of new isolates is usually complicated with conventional techniques which have to be adapted to each new strain. Even in well-established strains, the available transformation protocols often suffer from low efficiencies.

Results: In this paper, we provide a new broad host range E. coli/Bacillus shuttle vector, named pBACOV (Bacillus conjugation vector), that can be efficiently transferred to various Bacillus species using a single protocol. A variant of pBACOV carrying the sfGFP gene was successfully transferred to eight different species from the genus Bacillus and to one Paenibacillus species using triparental conjugation ("transmating"). This was achieved using a single protocol and worked for nine out of eleven tested acceptor species. The transmating procedure was used to test

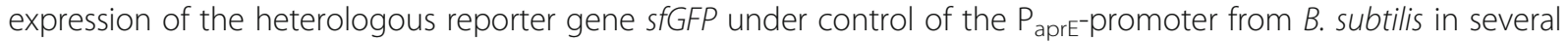
Bacillus species in parallel. Expression of sfGFP was found in eight out of nine transmates. For several of the tested species, this is the first report of a method for genetic modification and heterologous gene expression. The expression level, analyzed by measuring the relative sfGFP-fluorescence normalized to the cell density of the cultures, was highest in B. mojavensis.

Conclusions: The new shuttle vector pBACOV can be transferred to many different Bacillus and Paenibacillus species using a simple and efficient transmating protocol. It is a versatile tool facilitating the application of recombinant DNA technology in new as well as established strains, or selection of an ideal host for heterologous gene expression from a multitude of strains. This paves the way for the genetic modification and biotechnological exploitation of the broad diversity of species of Bacillus and related genera as well as different strains from these species.
\end{abstract}

Keywords: Triparental conjugation, Broad host range, Shuttle vector, sfGFP, Bacillus, Paenibacillus, Heterologous expression, Genetic modification, Plasmid transfer, Transmating

\footnotetext{
* Correspondence: petra.kornberger@tum.de

'Department of Microbiology, Technical University of Munich,

Emil-Ramann-Str. 4, D-85354 Freising-Weihenstephan, Germany

Full list of author information is available at the end of the article
}

(c) The Author(s). 2018 Open Access This article is distributed under the terms of the Creative Commons Attribution 4.0 International License (http://creativecommons.org/licenses/by/4.0/), which permits unrestricted use, distribution, and reproduction in any medium, provided you give appropriate credit to the original author(s) and the source, provide a link to the Creative Commons license, and indicate if changes were made. The Creative Commons Public Domain Dedication waiver (http://creativecommons.org/publicdomain/zero/1.0/) applies to the data made available in this article, unless otherwise stated. 


\section{Background}

Bacillus species are among the most extensively examined bacteria and are used for a variety of applications. Most prominent among them is Bacillus subtilis, which was the first Bacillus strain successfully transformed with purified DNA [1]. Today, B. subtilis and other members of the genus are major workhorses in industrial microbiology, mainly due to their ability to secrete large quantities of extracellular enzymes [2]. While species such as B. subtilis and B. licheniformis have already been isolated in the nineteenth century and are therefore well-known and widely applied, new species and strains continue to be isolated. Some of these new isolates have interesting properties for potential applications, but are not yet widely used. Additional File 1 gives a non-exhaustive overview of Bacillus strains which are already applied for the production of enzymes and metabolites, as well as rather "exotic" strains which are not yet applied but show promising characteristics. The listed species were also used in this study.

Recombinant DNA technology can greatly improve the performance of microorganisms for selected applications. Although Bacillus species exhibit promising characteristics, currently the Gram-negative Escherichia coli is the most widely used host for heterologous gene expression, especially in the context of metabolic engineering and production of small molecules. This is due to the fact that efficient genetic manipulation techniques and system-level strategies exist for this microorganism [3]. While efficient transformation protocols and methods for manipulation of the chromosome are available for B. subtilis, it is more challenging to perform such experiments with sufficient efficiency in other $\mathrm{Ba}$ cillus hosts, especially in wild-type strains which are difficult to modify genetically [2, 4]. One reason for this is that transformation of bacteria with plasmid DNA generally requires specified protocols and adaptation of the procedures for each strain.

Common methods to introduce recombinant DNA are the use of natural competence in case of B. subtilis, protoplast transformation (often used for B. megaterium), electroporation, and mobilization of plasmids from E. coli to Gram-positive recipients by conjugation. In most cases, the elaborate preparation of naturally or otherwise competent cells is required and usually, different methods are needed for different strains. In addition to the fact that the available methods are usually specific for one strain, they also have other drawbacks: protoplasts are difficult to handle and do not survive freezing; natural competence is observed in B. subtilis but not in most other Bacillus species and the efficiency is rather low; electroporation is an efficient method, but requires individual determination of ideal parameters such as medium composition and electric field strength [5-7].
In addition, it can be troublesome to transfer previously established genetic transformation methods (such as chemical/heat transformation, protoplast transformation or electroporation) even between strains of the same species, due to differences e.g. in special medium requirements (for example regeneration media after protoplast transformation) or differences in their restriction/ modification systems.

Methods for the efficient introduction of genes into multiple species and strains of bacilli without the need to adapt the protocol to each strain of interest are currently not available, but would be of high value, for example to enable fast examination which strain or species is best suited for expression of a given gene.

\section{Results}

To enable fast evaluation of the suitability of multiple bacterial species for heterologous gene expression and to assess their genetic accessibility, we established a new broad-host range shuttle vector in combination with a simple procedure for plasmid transfer by triparental conjugation. The method, named "transmating", should be suited for a broad variety of strains without the need of protocol adaptation for the individual strains. A schematic overview of the method is given in Fig. 1.

\section{Design of pBACOV}

The newly developed plasmid pBACOV (Bacillus conjugation vector) includes replication origins and selection markers for E. coli and Bacillus as well as the expression cassette from pBE-S and the RK2 conjugation origin (oriT/ traJ) from plasmid pKVM4, a mobilizable plasmid used to generate markerless gene deletions in B. licheniformis [8]. The expression cassette contains the B. subtilis promoter $\mathrm{P}_{\text {aprE}}$, the aprE signal peptide for secretory protein expression, a multiple cloning site (MCS) and the coding sequence for a C-terminal hexahistidine tag ( $\mathrm{His}_{6}$-tag) for protein purification (see Materials and Methods).

To generate pBACOV-sfGFP (Fig. 2), the sfGFP gene coding for super-folder green fluorescent protein [9] was inserted into pBACOV, while removing the aprE signal peptide. Thus, sfGFP is expressed intracellularly, allowing to compare promoter strength between different strains containing pBACOV-sfGFP without having to be concerned about additional influences that secretion might have on the level of sfGFP produced. The expected plasmid sequences of pBACOV and pBACOV-sfGFP were confirmed by sequencing.

Establishment of the minimal inhibitory concentrations of kanamycin and polymyxin B for all tested strains

The selection agar contained kanamycin (Kan) for the selection of colonies carrying the plasmid and polymyxin $\mathrm{B}$ (Pol) for counter-selection against the E. coli donor 


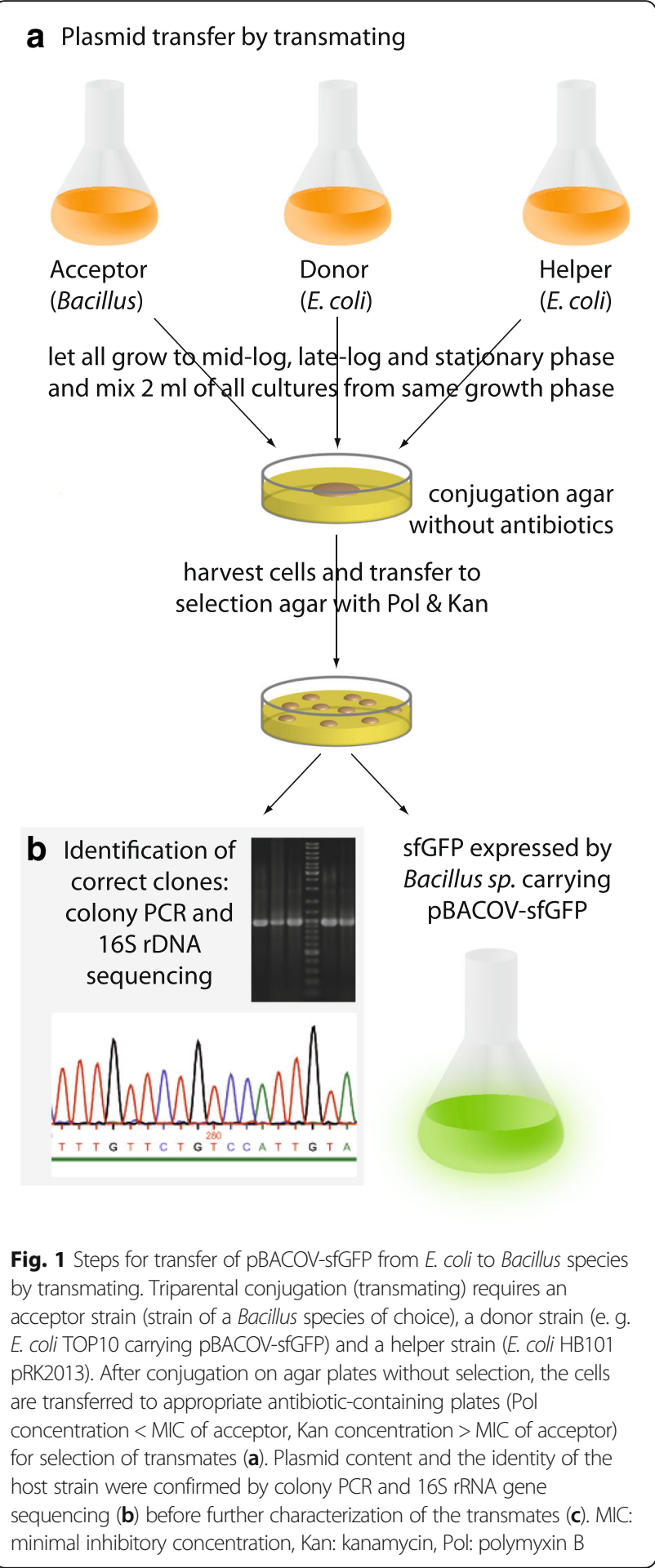

and helper strains. The antibiotic concentration in the selection agar must be adjusted such that the sensitivity toward Kan was high enough to enable selection for colonies carrying the plasmid, while sufficient resistance against Pol was necessary to ensure effective counter-selection against E. coli. The standard concentration of antibiotics in the

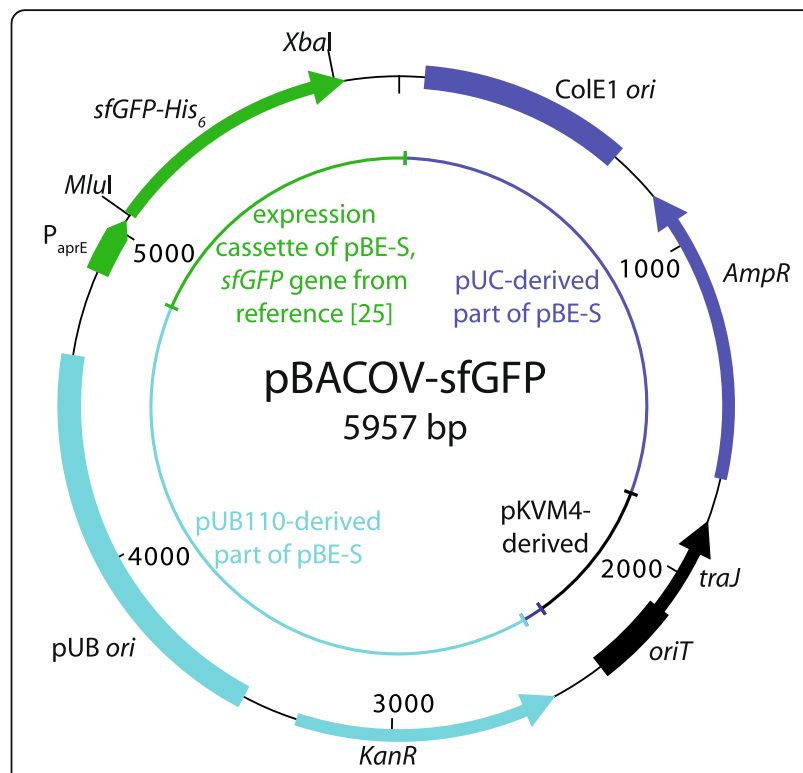

Fig. 2 Schematic map of the shuttle vector pBACOV with the inserted target gene sfGFP. ColE1 ori: origin of replication for E. coli; AmpR: Ampicillin resistance gene for selection in E. coli; oriT/traJ: origin of transfer for conjugative plasmid transfer; KanR: Kanamycin resistance gene for selection in Bacillus; pUB ori: origin of replication for Bacillus; PaprE: aprE promoter from B. subtilis; sfGFP-His6: target gene sfGFP fused with a sequence encoding a C-terminal $\mathrm{His}_{6}$-tag

selection agar was $10 \mu \mathrm{g} / \mathrm{ml}$ for Kan and $40 \mu \mathrm{g} / \mathrm{ml}$ for Pol. These concentrations were found to be suited for B. licheniformis DSM13, B. pumilus DSM27, B. sonorensis DSM13779 and Paenibacillus polymyxa DSM356. Other Bacillus species tested showed resistance to $10 \mu \mathrm{g} / \mathrm{ml}$ Kan or sensitivity to $40 \mu \mathrm{g} / \mathrm{ml} \mathrm{Pol}$. In these cases, the minimal inhibitory concentrations of Kan or Pol had to be established by serial dilution tests before transmating with pBACOV-sfGFP could be attempted. The results of the serial dilution tests are listed in Additional File 2. Based on these results, seven additional strains were selected for transmating experiments with adapted concentrations of the selection antibiotics: B. mycoides DSM2048, B. megaterium DSM32, B. pseudomycoides DSM12442 (concentrations used: Pol: $40 \mu \mathrm{g} / \mathrm{ml}$, Kan: $50 \mu \mathrm{g} / \mathrm{ml}$ ), B. subtilis RIK1285, B. mojavensis DSM9205, B. vallismortis DSM11031 (Pol: $10 \mu \mathrm{g} / \mathrm{ml}$, Kan: $10 \mu \mathrm{g} / \mathrm{ml}$ ) and B. oleronius WS8036 (Pol: $2.5 \mu \mathrm{g} / \mathrm{ml}$, Kan: $10 \mu \mathrm{g} / \mathrm{ml}$ ).

\section{Transmating pBACOV-sfGFP to different Bacillus species} Plasmid pBACOV-sfGFP, which was constructed as a derivative of vector pBACOV (see above and Fig. 2), was used to study (i) transfer to a large number of different Bacillus species by a single routine transmating procedure and (ii) the expression of the heterologous reporter gene $s f G F P$ in all transmates.

The transfer of pBACOV-sfGFP from E. coli TOP10 to various Bacillus acceptor strains was achieved by 
transmating using E. coli HB101 pRK2013 as helper strain $[10,11]$ as described in Material \& Methods. Plasmid pRK2013 is a self-transmissible plasmid (size: 48 $\mathrm{kbp})$ containing the broad host range transfer system of RK2 [10, 12]. It is efficiently transferred between Gram-negative bacteria and can promote the conjugal transfer of unrelated plasmids $[10,12]$. The mechanism for triparental plasmid transfer is thought to involve two steps: first, the helper plasmid pRK2013 is transferred to the donor strain which carries the mobilizable, but not self-transmissible, expression plasmid pBACOV. Now, the genes necessary for conjugation can be expressed in the donor strain and thus the expression plasmid pBACOV can be transferred to the acceptor strain. For each acceptor strain, three transmating batches were made. These contained either cells from the overnight pre-cultures, cells from the mid-exponential growth phase $\left(\mathrm{OD}_{600}\right.$ between 0.6 and 0.9 ) or cells from the late exponential phase $\left(\mathrm{OD}_{600} \geq 1.2\right)$. After incubation of the selection plates, colonies were counted and correct transmates were identified by analytical PCR using plasmid specific primers (pBACOV-seq_4894fw and pBACOV-Seq-rv). The $16 \mathrm{~S}$ rRNA gene sequence of selected transmates was determined to verify that the clones obtained after selection/counter-selection belonged to the correct acceptor species. This was especially important for $B$. mojavensis, $B$. vallismortis and $B$. oleronius, i. e. the strains grown at reduced Pol concentrations, in order to eliminate the possibility of growth of $E$. coli under these milder counter-selection conditions. Additionally, special attention was paid to the colony morphology: to determine the transmating efficiency, only colonies with the morphology typical for the respective acceptor strains were considered. The Pol concentration of $10 \mu \mathrm{g} / \mathrm{ml}$ used for the matings with $B$. mojavensis and $B$. vallismortis could not inhibit growth of $E$. coli completely, since some of the tested colonies were $E$. coli, while others were Bacillus transmates. Here, the colony morphology was helpful for the identification of correct clones as a prescreening before $16 \mathrm{~S}$ rRNA gene sequencing. In the case of B. oleronius all colonies chosen from the selection plates for $16 \mathrm{~S}$ rRNA gene sequencing turned out to be $E$. coli. This indicates that although the minimal inhibitory Pol concentration for $E$. coli in liquid cultures was below $2.5 \mu \mathrm{g} / \mathrm{ml}$, effective counter-selection against $E$. coli was not possible on agar plates at this concentration. Thus, transfer of pBACOV-sfGFP to $B$. oleronius was regarded as not successful.

Transfer of pBACOV-sfGFP to all other selected acceptor strains was successful with the only exception of $B$. megaterium. The total number of colonies on selection agar varied between the different species as well as the three transmating batches for each strain, but was never below 25 (for examples of yielded colony numbers, see Table 1). The most colonies were obtained with $P$. polymyxa DSM356 (total number of colonies: 1750) and B. subtilis RIK1285 (several thousand colonies, partially confluent growth on selection plates).

\section{Measurement of sfGFP fluorescence}

Production of sfGFP by selected transmates was studied in order to demonstrate the usefulness of pBACOV as broad host range expression plasmid. Non-transmated cultures of the same species served as negative controls. SM-Cas medium was used, because autofluorescence was not detectable with this medium. After $24 \mathrm{~h}$ of incubation, the cultures were diluted to an $\mathrm{OD}_{600}$ of about 1 and the fluorescence was measured (excitation: $470 \mathrm{~nm}$, emission: $520 \mathrm{~nm}$ ). Table 2 summarizes the relative fluorescence normalized to the $\mathrm{OD}_{600}$ of the cultures (fluorescence intensity/ $\left.\mathrm{OD}_{600}\right)$. In eight out of nine cultures of strains carrying pBACOV-sfGFP, sfGFP-fluorescence was detectable, which shows that the $\mathrm{P}_{\text {apre-promoter is functional in these bac- }}$ teria. $B$. sonorensis was the only transmated species which did not show detectable sfGFP fluorescence. Hence, $\mathrm{P}_{\mathrm{aprE}}$ can be used for the expression of heterologous genes in almost $90 \%$ (eight of nine) of the tested strains. The strongest relative fluorescence was observed with $B$. mojavensis. The sfGFP-fluorescence was also visualized by fluorescence microscopy. Images of B. licheniformis, B. mojavensis and $P$. polymyxa with or without pBACOV-sfGFP are shown in Fig. 3.

\section{Discussion}

Conjugal transfer of plasmid DNA from Gram-negative E. coli to Gram-positive bacteria has been reported

Table 1 Yield of colonies obtained in representative transmating experiments with each acceptor strain

\begin{tabular}{ll}
\hline Species & $\begin{array}{l}\text { number of colonies } \\
\text { with typical morphology }\end{array}$ \\
\hline B. subtilis & $>5000^{*}$ \\
P. polymyxa & 1750 \\
B. vallismortis & 849 \\
B. pumilus & 655 \\
B. mojavensis & 574 \\
B. sonorensis & 178 \\
B. licheniformis & 37 \\
B. mycoides & n. q. ${ }^{* *}$ \\
B. pseudomycoides & n. q. ${ }^{* *}$ \\
B. oleronius & 0 \\
B. megaterium & 0
\end{tabular}

Only colonies with the typical morphology of the respective acceptor strain were counted. On selection plates with polymyxin B concentrations $\leq 10 \mu \mathrm{g} /$ $\mathrm{ml}$, additional growth of $E$. coli was observed. *: for B. subtilis, several thousand distinct colonies and partially confluent growth were observed. ${ }^{*}$ : for $B$. mycoides and B. pseudomycoides, the exact number of colonies could not be quantified (n.q.), due to confluent growth of large, mycelium-like colonies (diameter $>10 \mathrm{~mm}$ ) 
Table 2 sfGFP fluorescence of different bacterial species carrying pBACOV-sfGFP relative to B. subtilis RIK1285 pBACOVsfGFP

\begin{tabular}{lll}
\hline Species & \multicolumn{2}{l}{ Relative fluorescence [\%] } \\
\cline { 2 - 3 } & pBACOV-sfGFP & wild-type \\
\hline B. mojavensis & $383 \pm 5.1$ & n. d. \\
B. vallismortis & $239 \pm 5.9$ & $0.9 \pm 0.1$ \\
B. licheniformis & $160 \pm 8.8$ & n. d. \\
B. subtilis & $100 \pm 0.6$ & n. d. \\
B. pumilus & $56.1 \pm 0.9$ & n. d. * \\
B. pseudomycoides & $41.0 \pm 1.5$ & n. d. \\
P. polymyxa & $16.7 \pm 0.5$ & $3.4 \pm 0.2$ \\
B. mycoides & $14.9 \pm 0.1$ & $3.1 \pm 0.0$ \\
B. sonorensis & n. d. & $1.1 \pm 0.1$ \\
\hline
\end{tabular}

Strains were grown for $24 \mathrm{~h}$ at $37^{\circ} \mathrm{C}, 180 \mathrm{rpm}$ (B. mycoides: $72 \mathrm{~h}$ at $30^{\circ} \mathrm{C}$ $180 \mathrm{rpm}$ ) in SM-Cas medium with supplements, if appropriate. For details, see Material \& Methods. Fluorescence was detected with cultures diluted to $\mathrm{OD}_{600}=1$ and the fluorescence intensity (excitation: $470 \mathrm{~nm}$, emission $520 \mathrm{~nm}$ ) and the $\mathrm{OD}_{600}$ were determined. The relative fluorescence (fluorescence intensity $/ \mathrm{OD}_{600}$ ) was calculated by normalizing the measured fluorescence intensity by the $\mathrm{OD}_{600}$. The relative fluorescence of $B$. subtilis RIK1285 pBACOV-sfGFP was defined as $100 \%$. The given values are mean values \pm standard deviation of triplicate measurements. The asterisk * indicates that the $B$. pumilus wild-type culture did not reach an $\mathrm{OD}_{600}$ of 1 within the $24 \mathrm{~h}$ of incubation and therefore was not diluted for fluorescence measurements. n. d.: not detectable (defined as relative fluorescence $<0.7 \%$ )

before [13, 14], including $B$. licheniformis and thermophilic Bacillus strains [4, 14, 15], but no comprehensive study exists showing the versatility of this gene transfer method to introduce plasmids into various different species of mesophilic bacilli. Plasmid pBACOV, introduced in this work, is a new broad host range vector which can easily be transferred to an acceptor strain of choice using triparental conjugation ("transmating") and can be used for heterologous gene expression in various Bacillales species. pBACOV-sfGFP, containing sfGFP as reporter gene, was successfully transferred to strains of widely used and well-studied species such as B. licheniformis or B. subtilis, but also to more "exotic" species. To our knowledge, this is the first report of recombinant DNA technology applied in B. sonorensis, B. mycoides, B. pseudomycoides, $B$. vallismortis and $B$. mojavensis, thus making these species accessible for genetic engineering. Since Bacillus species in general have high potential for biotechnological applications, there is a great interest in expanding the number of genetically accessible strains. Usage of the pBACOV vector in combination with the transmating protocol described herein can pave the way to future applications.

In this study, we strived to test the applicability of pBACOV and our transmating method in as many species as possible from the genus Bacillus and closely related genera. While the majority of the tested strains belonged to the genus Bacillus, pBACOV also worked in the genus Paenibacillus, as was demonstrated with $P$. polymyxa DSM356. The pUB origin of replication stems from Staphylococcus aureus and is known to be active in a wide range of low GC Gram-positive bacteria (Firmicutes), including anaerobic Clostridia $[16,17]$. Therefore it is likely that pBACOV can be transferred to even more genera.

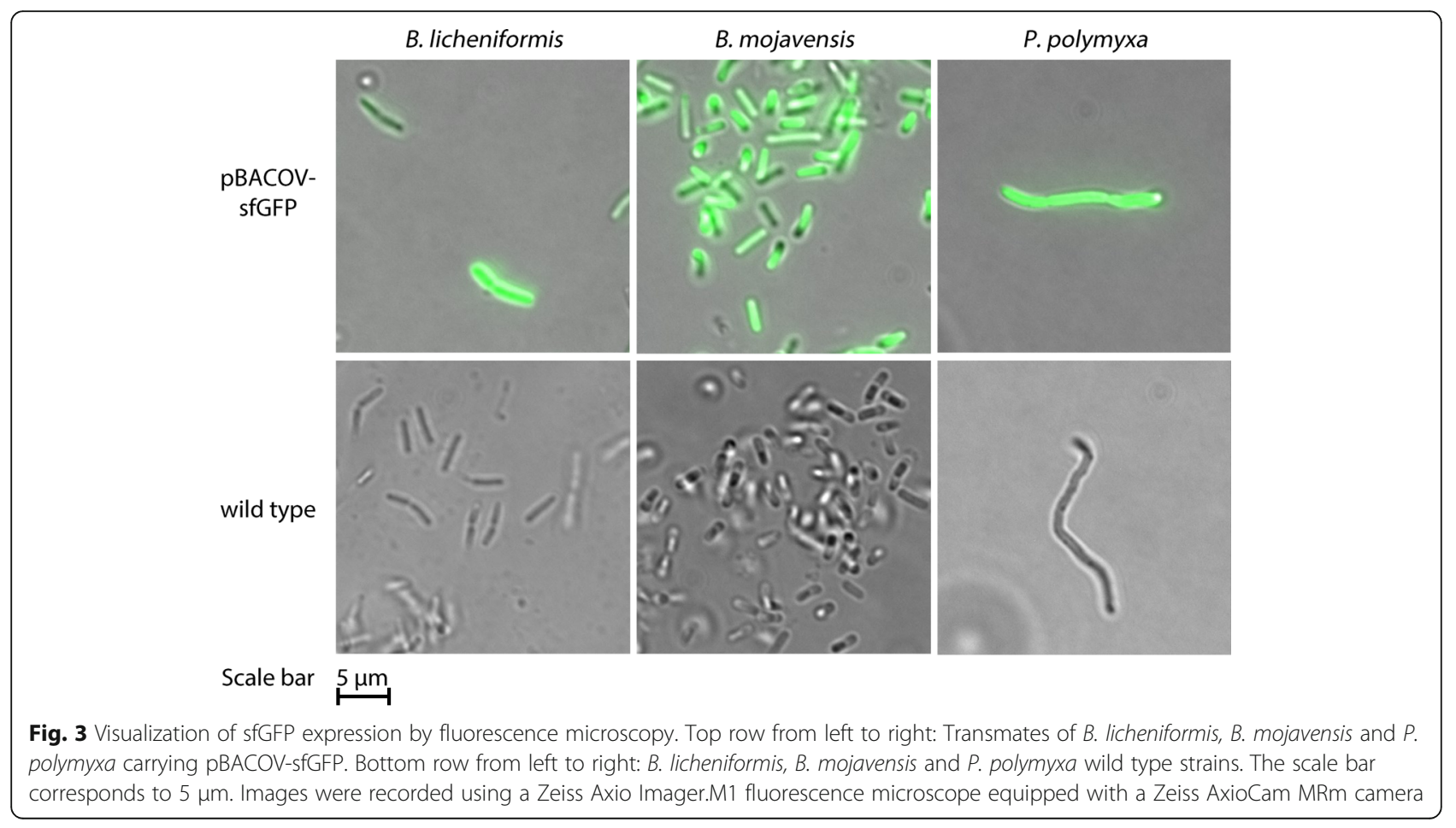


In this study we did not aim to optimize the frequency of transfer between the E. coli donor and the acceptor bacilli but rather wanted to develop a simple, versatile method that can be applied to many strains without extensive adaptation to the different acceptor strains. In our hands, transmates were obtained for nine of the eleven Bacillus and Paenibacillus species tested. Transmating failed in only two of the cases tested, i.e. for $B$. megaterium DSM32 and B. oleronius WS8036. Regarding $B$. megaterium, the reason for the failed transmating is not known, but the cell envelope composition [18] or other special features may play a role.

To express heterologous target genes, pBACOV features the $\mathrm{P}_{\mathrm{aprE}}$ promoter from B. subtilis [19-22]. We demonstrate that $\mathrm{P}_{\mathrm{aprE}}$ is functional in seven additional Bacillus species using sfGFP as a reporter gene and report for the first time heterologous gene expression in four new Bacillus species (B. mojavensis, B. mycoides, $B$. pseudomycoides and $B$. vallismortis). The observed sfGFP expression levels ranged between about 0.15- and 3.8 -fold of the value measured in $B$. subtilis. The reasons for the up to 25 -fold differences in the apparent sfGFP expression levels found between different host strains are currently unknown, but various differences between the hosts' gene expression machineries (differences in promoter $\mathrm{P}_{\mathrm{aprE}}$ recognition, mRNA stability, sfGFP folding efficiency etc.) and also differences in the plasmid's copy number may contribute to this observation.

It is possible to obtain large numbers of colonies with some strains (e.g. P. polymyxa DSM356, B. subtilis RIK1285). This makes the transmating system suitable for the screening of libraries, e. g. signal peptide libraries, in some of the new host strains from this work for optimizing the expression of a secretory protein of interest. This holds true even for species where fewer colonies were obtained, as the procedure can be easily scaled up. This is a big advantage over transformation procedures using purified plasmid DNA, where purification of large quantities of plasmid DNA is needed.

One limitation of our system is that sensitivity to Kan and resistance to Pol are prerequisites for the acceptor strain. Of the 24 bacteria included in this study, only 10 (approx. 42\%) showed the necessary characteristics. The selection for transmates relies on Kan resistance conferred by the plasmid. By replacing the Kan resistance cassette of pBACOV with a different selection marker (such as chloramphenicol or tetracycline resistance), or by equipping the vector with two or even three selection markers, it should be possible to increase the versatility of pBACOV. For counter-selection against the E. coli donor and helper strains, the minimal inhibitory concentration of Pol is critical. In our experience, a concentration of at least $10 \mu \mathrm{g} / \mathrm{ml} \mathrm{Pol}$ is required for sufficient counter-selection. At the attempt to transfer pBACOV-sfGFP to B. oleronius at a
Pol concentration of $2.5 \mu \mathrm{g} / \mathrm{ml}$, a substantial number of $E$. coli colonies was detected on the selection agar. In some instances, colonies of $E$. coli even grew at $10 \mu \mathrm{g} / \mathrm{ml}$, resulting in false-positive clones which had to be eliminated via rigorous discriminating tests. In this work we used assessment of the characteristic colony morphology and $16 \mathrm{~S}$ rRNA gene sequencing for the unequivocal identification of the $B$. mojavensis and $B$. vallismortis transmates, but other methods, including Gram-staining or differentiating physiological tests may also be useful to discriminate between real acceptor strain transmates and false-positive E. coli clones. Alternative options for effective counter-selection against $E$. coli could include the use of spontaneous antibiotic-resistant mutants of the acceptor strain or culture media which inhibit growth of E. coli, such as MRS agar [23].

\section{Conclusions}

This study introduces a universal, simple and efficient method for the transfer of plasmid DNA into a large number of different Bacillus and Paenibacillus species. We stress that the same procedure worked for most tested strains without the need for individual optimization. The use of pBACOV enabled for the first time the demonstration of heterologous gene expression in B. mojavensis, $B$. mycoides, $B$. pseudomycoides, and $B$. vallismortis. Its expression promoter $\mathrm{P}_{\mathrm{aprE}}$ from $B$. subtilis was functional in eight out of nine transmated species.

The new plasmid pBACOV in combination with the transmating protocol facilitates application of recombinant DNA technology in new as well as established Bacillus and Paenibacillus strains. It can aid in the selection of the best-suited host for heterologous gene expression from a large number of candidate strains, thereby enabling the research community to tap into the abundant source of hitherto unused Bacillus species with potential for application in biotechnology.

\section{Methods}

Bacterial strains and growth conditions:

The bacterial strains used in this study are listed in Additional File 2. All Bacillus and Paenibacillus strains were obtained from DSMZ (Leibniz-Institut DSMZ-Deutsche Sammlung von Mikroorganismen und Zellkulturen $\mathrm{GmbH}$, Braunschweig, Germany), except B. bataviensis WS4576, B. ginsengihumi WS8095, B. horikoshii WS2157, B. niabensis WS9147, B. niacini WS4575, B. oleronius WS8036, Fictibacillus arsenicus WS4538 (obtained from the strain collection of the Chair for Microbial Ecology, Department of Biosciences, Technical University of Munich, Freising, Germany) and B. subtilis RIK1285 (Takara-Bio Inc., Kusatsu, Japan). E. coli TOP10 (Life technologies, Carlsbad, USA) was used for cloning and as donor strain in transmating experiments. E. coli HB101 carrying the 
plasmid pRK2013 (DSMZ 5599) [10, 11] was used as helper strain for transmating experiments. All strains were routinely grown in LB liquid medium [24] or agar plates at $37^{\circ} \mathrm{C}$ (liquid cultures were shaken at $180 \mathrm{rpm}$ ), except for B. mycoides, which was grown at $30{ }^{\circ} \mathrm{C}$. E. coli $\mathrm{HB} 101$ pRK2013 was grown with $50 \mu \mathrm{g} / \mathrm{ml}$ kanamycin (AppliChem GmbH, Darmstadt, Germany) and E. coli TOP10 carrying pBACOV or pBACOV-sfGFP was grown with $100 \mu \mathrm{g} / \mathrm{ml}$ carbenicillin (Carl Roth $\mathrm{GmbH}$, Karlsruhe, Germany). Bacillus transmates were streaked on LB selection agar containing polymyxin B (Carl Roth $\mathrm{GmbH}$ ) and Kan (for the applied concentrations see below, section "plasmid transfer by transmating") or grown in liquid LB medium with Kan (same concentrations as the selection agar).

\section{Construction of pBACOV and pBACOV-sfGFP}

To construct pBACOV, Gibson Assembly of three overlapping DNA fragments was applied [25], using the commercially available pBE-S plasmid (Takara-Bio Inc., size: $5938 \mathrm{bp}$ ) as chassis. pBE-S is composed of a fragment of the pUC plasmid, comprising the ColE1 origin of replication and ampicillin resistance gene (bp 1645-3556 of pBE-S) for propagation in E. coli, and a piece of plasmid pUB110, including the pUB origin of replication and the kanamycin resistance gene for Bacillus (bp 3557-5936 of pBE-S). Furthermore, an expression cassette is present after the pUB ori (bp 5937-517 of pBE-S). The expression cassette consists of the B. subtilis promoter $\mathrm{P}_{\mathrm{aprE}}$, the aprE signal peptide for secretory protein expression, a multiple cloning site (MCS) and the coding sequence for a C-terminal hexahistidine tag $\left(\mathrm{His}_{6}{ }^{-} \mathrm{tag}\right)$ for protein purification. A stem-loop was predicted from bp 486 to 519, followed by a stretch of five $\mathrm{T}$ nucleotides, constituting a potential rho-independent transcriptional terminator. For construction of pBACOV, (i) an un-annotated segment of pBE-S (bp 580-1642 of pBE-S) was removed and (ii) a
oriT/traJ region necessary for conjugative plasmid transfer was inserted between the antibiotic resistance genes.

Fragment 1 for Gibson Assembly (i. e. the pUB110-derived region and expression cassette, bp 3453-557 of pBE-S) was created using the primers pUB110_backbone_fw and pUB110_backbone_rv with pBE-S as template. Fragment 2 (the pUC-derived portion of pBE-S, bp 1642-3452) was amplified using the primers Fw_pUC_for_Gibson and Rv_pUC_from_pBE-S and pBE-S as template. Fragment 3 (oriT/traJ) was amplified by using the primers oriT_traJ_fw and oriT_traJ_rv and the plasmid pKVM4 as template [8]. To maintain compatibility of pBACOV with the signal peptide library from the B. subtilis Secretory Protein Expression System Kit (Takara-Bio Inc.), the EagI restriction site within the traJ gene was removed by two-step QuikChange mutagenesis [26] using primers QC_g2015t_1 and QC_g2015t_2. The incorporated mutation (g2015t) is silent, exchanging the original alanine-codon GCC to GCA while removing the EagI restriction site (CGGCCG is mutated to CTGCCG). For construction of pBACOV-sfGFP, the sfGFP-gene was amplified using the primers sfGFP-fw and sfGFP-rv and the plasmid pET28A-sfGFP (kindly provided by Mark Teese) as template. The sfGFP coding sequence corresponds to the sequences published in [27]. pBACOV was linearized using the restriction endonucleases $M l u \mathrm{I}$ and $X b a \mathrm{I}$, thereby removing the coding sequence of the aprE signal peptide. $s f G F P$ was inserted into $\mathrm{pBACOV}$ using Gibson Assembly. All primers used are listed in Table 3.

The vector sequences of pBACOV (accession number: MG599120.1) and pBACOV-sfGFP (accession number:MG599121.1) were deposited at GenBank.

\section{Determination of minimal inhibitory concentrations of kanamycin and polymyxin B}

A single colony of the respective strain was carefully resuspended in $20 \mathrm{ml} \mathrm{LB}$ medium. Four glass test tubes

Table 3 Primers used in this study

\begin{tabular}{ll}
\hline Primer Name & Sequence 5' - 3 $^{\prime}$ \\
\hline pUB110_backbone_fw & GTCTAAGAAACCATTATTATCATGAC \\
pUB110_backbone_rv & CATAATAGTTATGCAGTTTGTAGAATGC \\
Fw_pUC_for_Gibson & CAAACTGCATAACTATTATGTACGAGCAAAAGGCCAGC \\
Rv_pUC_from_pBE-S & GTCAGGTGGCACTITTCG \\
oriT_traJ_fw & TCCCCGAAAAGTGCCACCTGACTTAGTGCTTTACGGCACCTCG \\
oriT_traJ_rv & CATGATAATAATGGTTTCTTAGACGCTTCGGGGTCATTATAGCG \\
sfGFP-fw & TAAGCAAAAGGAGAGGGACGCGTATGAGCAAAGGTGAAGAACTG \\
sfGFP-rv & CATTAGTGGTGATGATGGTGATGTCTAGATTATACAGTTCATCCATACCATG \\
pBACOV-seq_4894fw & CGAGTCTCTACGGAAATAGC \\
pBACOV-Seq-rv & CGATGAGCGCATTGTTAG \\
QC_g2015t_1 & GCGGCGGCGGCAGGCATGAGCCTG \\
QC_g2015t_2 & CAGGCTCATGCCTGCCGCCGCCGC \\
\hline
\end{tabular}


were each filled with $2.5 \mathrm{ml}$ of this suspension while a fifth glass test tube was filled with $5 \mathrm{ml}$. The $5 \mathrm{ml}$ culture was supplemented with Kan (final concentration: $200 \mu \mathrm{g} / \mathrm{ml}$ ) or Pol (final concentration: $40 \mu \mathrm{g} / \mathrm{ml}$ ). Then, a dilution series was made by transferring $2.5 \mathrm{ml}$ from one tube to the next, which resulted in a 2-fold dilution of the antibiotic per step (from $200 \mu \mathrm{g} / \mathrm{ml}$ to $12.5 \mu \mathrm{g} / \mathrm{ml} \mathrm{Kan}$; from $40 \mu \mathrm{g} / \mathrm{ml}$ to $2.5 \mu \mathrm{g} / \mathrm{ml} \mathrm{Pol}$ ). The tubes were incubated overnight at $180 \mathrm{rpm}$ at the growth temperature of the respective test strain (see above). The minimal inhibitory concentration (MIC) was defined as the lowest concentration at which no growth was detectable.

\section{Plasmid transfer by transmating}

To prepare pre-cultures for transmating experiments, $100 \mathrm{ml}$ Erlenmeyer flasks containing $20 \mathrm{ml} \mathrm{LB}$ medium (supplemented with antibiotics if appropriate) were inoculated with single colonies of the Bacillus acceptor strain(s), the donor strain (E. coli TOP10 pBACOV-sfGFP) and the helper strain (E. coli HB101 pRK2013), respectively. The pre-cultures were incubated overnight as indicated above. The next day, the $\mathrm{OD}_{600}$ of all cultures was determined and the cultures were used to inoculate fresh flasks with $20 \mathrm{ml} \mathrm{LB}$ (supplemented with antibiotics if appropriate) to an $\mathrm{OD}_{600}$ of 0.2. The overnight pre-cultures were stored on ice for later use. The $\mathrm{OD}_{600}$ of the freshly inoculated flasks was checked regularly, starting $90 \mathrm{~min}$ after the beginning of incubation. Once the $\mathrm{OD}_{600}$ was between 0.6 and $0.9,2 \mathrm{ml}$ samples of each culture were taken and stored on ice. Incubation of the main cultures was continued until the $\mathrm{OD}_{600}$ was at least 1.2, at which point another round of $2 \mathrm{ml}$ samples was collected and stored on ice. The collected donor, acceptor and helper samples of the same growth phase (overnight, $\mathrm{OD}_{600}$ between 0.6 and 0.9 or $\mathrm{OD}_{600} \geq 1.2$ ) were then mixed as follows: $2 \mathrm{ml}$ of the donor cells were pelleted by centrifugation and the supernatant was discarded. All centrifugation steps were carried out at $1900 \mathrm{x} \mathrm{g}, 4{ }^{\circ} \mathrm{C}$, for $5 \mathrm{~min}$. The donor cell pellet was resuspended in $2 \mathrm{ml}$ of acceptor culture and centrifuged again. The pellet was resuspended in $2 \mathrm{ml}$ of the helper culture and centrifuged. The resulting pellet containing all three strains was washed twice with $1 \mathrm{ml}$ of LB to remove traces of antibiotics. The cell pellet was resuspended in a small volume of remaining supernatant. Sterile cellulose acetate filters (pore size: $0.2 \mu \mathrm{m}$, diameter: $25 \mathrm{~mm}$, Sartorius Stedim Biotech GmbH, Göttingen, Germany) were placed on LB agar plates and the mating mixtures were pipetted smoothly, with as little shearing as possible, to the middle of the filters. These conjugation plates were incubated overnight at $30{ }^{\circ} \mathrm{C}$ (three plates for each acceptor strain, each containing one mixture of donor/acceptor/helper cultures with the same $\left.\mathrm{OD}_{600}\right)$. The next day, the filters were carefully removed from the LB agar plates and placed into $5 \mathrm{ml}$
Eppendorf reaction tubes (Eppendorf AG, Hamburg, Germany). The cells were harvested from the filters by adding $1 \mathrm{ml}$ of LB medium and vortexing. These cell suspensions were then plated onto selection agar plates (LB agar containing Pol and Kan) and incubated overnight at $37{ }^{\circ} \mathrm{C}$ or for up to three days at $30{ }^{\circ} \mathrm{C}$ until colonies appeared. Routinely, the selection agar contained $10 \mu \mathrm{g} / \mathrm{ml} \mathrm{Kan}$ and $40 \mu \mathrm{g} / \mathrm{ml}$ Pol. For Bacillus strains sensitive toward $40 \mu \mathrm{g} / \mathrm{ml}$ Pol or resistant against $10 \mu \mathrm{g} / \mathrm{ml} \mathrm{Kan}$, the respective antibiotic concentration was adapted based on the determined MIC as follows: $40 \mu \mathrm{g} / \mathrm{ml}$ Pol and $50 \mu \mathrm{g} / \mathrm{ml}$ Kan for B. mycoides, B. megaterium and B. pseudomycoides; $10 \mu \mathrm{g} / \mathrm{ml} \mathrm{Pol} \mathrm{and}$ $10 \mu \mathrm{g} / \mathrm{ml} \mathrm{Kan}$ for B. subtilis, B. mojavensis and B. vallismortis, and $2.5 \mu \mathrm{g} / \mathrm{ml}$ Pol and $10 \mu \mathrm{g} / \mathrm{ml}$ Kan for $B$. oleronius. Correct transmates were identified by analytical PCR using two plasmid specific primers and by sequencing of the 16S rRNA gene using the primers $616 \mathrm{~V}$ and 630R [28].

\section{Expression of sfGFP and determination of relative fluorescence}

SM-Cas medium, based on Spizizen's Minimal Medium $[1,29]$, was used for sfGFP-expression experiments. The medium corresponds to the SM medium published online at SubtiWiki [30], with the addition of $1 \mathrm{~g} / \mathrm{l}$ casamino acids but without tryptophane. The final composition of SM-Cas medium was $17.5 \mathrm{~g} / \mathrm{l} \mathrm{K}_{2} \mathrm{HPO}_{4}, 7.5 \mathrm{~g} / \mathrm{K} \mathrm{KH}_{2} \mathrm{PO}_{4}$, $5 \mathrm{~g} / \mathrm{l}$ glucose, $4 \mathrm{~g} / \mathrm{l} \mathrm{L}$-glutamate, $2 \mathrm{~g} / \mathrm{l}\left(\mathrm{NH}_{4}\right)_{2} \mathrm{SO}_{4}, 1.26 \mathrm{~g} / \mathrm{l}$ trisodium citrate dihydrate, $1 \mathrm{~g} / \mathrm{l}$ casamino acids, $250 \mathrm{mg} / \mathrm{l}$ $\mathrm{MgSO}_{4}, 5.5 \mathrm{mg} / \mathrm{l} \mathrm{CaCl}, 1 \mathrm{mg} / \mathrm{l} \mathrm{MnCl} 2.4 \mathrm{H}_{2} \mathrm{O}, 1.7 \mathrm{mg} / \mathrm{l}$ $\mathrm{ZnCl}_{2}, 0.33 \mathrm{mg} / \mathrm{l} \mathrm{CuCl}_{2} \cdot 2 \mathrm{H}_{2} \mathrm{O}, 0.6 \mathrm{mg} / \mathrm{l} \mathrm{CoCl} \mathrm{Cl}_{2} \cdot 6 \mathrm{H}_{2} \mathrm{O}$, $0.6 \mathrm{mg} / \mathrm{l} \mathrm{Na} 2 \mathrm{MoO}_{4} \cdot 2 \mathrm{H}_{2} \mathrm{O}, 1.35 \mathrm{mg} / \mathrm{l} \mathrm{FeCl} \cdot 6 \mathrm{H}_{2} \mathrm{O}$. For $P$. polymyxa DSM356, biotin was added to a final concentration of $150 \mu \mathrm{g} / \mathrm{l}$ and for the tryptophan auxotrophic $B$. subtilis RIK1285 tryptophan was added to a final concentration of $50 \mathrm{mg} / \mathrm{l}$. $20 \mathrm{ml}$ of SM-Cas (with Kan at appropriate concentrations) were inoculated with a single colony of the Bacillus transmates carrying pBACOV-sfGFP or the respective wild-type strains as negative controls and incubated at $37{ }^{\circ} \mathrm{C}, 180 \mathrm{rpm}$ (B. mycoides: $30^{\circ} \mathrm{C}$ ). After $24 \mathrm{~h}$ (B. mycoides: $72 \mathrm{~h}$ ), the $\mathrm{OD}_{600}$ of the cultures was measured. For determination of the relative fluorescence normalized to cell density, the cultures were diluted with SM-Cas to $\mathrm{OD}_{600}=1$. Next, the $\mathrm{OD}_{600}$ and the fluorescence intensity (excitation: $470 \mathrm{~nm}$, emission: $520 \mathrm{~nm}$ ) were measured using Uvette ${ }^{\circ}$ cuvettes (Eppendorf) with a path length of $2 \mathrm{~mm}$ in a BioSpectrometer Fluorescence Photometer (Eppendorf). To calculate the relative fluorescence, the fluorescence intensity value was divided by the measured $\mathrm{OD}_{600}$, taking the path length of the cuvette into account. Each measurement was performed in triplicate. 


\section{Additional files}

Additional file 1: Table 1. Selection of well-known and exotic Bacillus species with some of their products and properties (including references). The listed species were also used in this study. (DOCX $20 \mathrm{~kb}$ )

Additional file 2: Table 2. Strains used in this study and determination of MIC of Kan or Pol (including references). (DOCX $19 \mathrm{~kb}$ )

\section{Abbreviations}

Kan: Kanamycin; MIC: Minimal inhibitory concentration; $\mathrm{OD}_{600}$ : Optical density at 600 nm; Pol: Polymyxin B; sfGFP: Super-folder green fluorescent protein

\section{Acknowledgements}

The authors thank the following people from the Department of Microbiology, Technical University of Munich, Freising, Germany: Dr. Armin Ehrenreich for helpful discussions about triparental conjugation, Ching-Ning Huang and Dr. David Kostner for providing the plasmid pKVM4 and E. coll HB101 pRK2013. The authors also thank Mark Teese, Chair of Biopolymer Chemistry, Technical University of Munich, Freising, Germany, for providing the plasmid pET28a-sfGFP. Special thanks goes to Gertrud Huith and Prof. Dr. Siegfried Scherer (Chair for Microbial Ecology, Department of Biosciences, Technical University of Munich, Freising, Germany) for providing strains from the collection of their institute.

\section{Funding}

Financial support for this work from the German Federal Ministry of Education and Research (FKZ 031A555, Bioeconomy International 2014) is gratefully acknowledged. This work was supported by the German Research Foundation (DFG) and the Technical University of Munich (TUM) in the framework of the Open Access Publishing Program. The funding bodies had no role in the design of the study and collection, analysis, and interpretation of data and in writing the manuscript.

\section{Availability of data and materials}

The datasets used and/or analyzed during the current study are available from the corresponding author on reasonable request.

\section{Authors' contributions}

SH, PK, WS, WZ and WL designed the research. SH and CG performed the experiments. SH and PK analyzed the data. All authors wrote and approved the final manuscript.

\section{Ethics approval and consent to participate}

Not applicable.

\section{Competing interests}

The authors declare that they have no competing interests.

\section{Author details}

'Department of Microbiology, Technical University of Munich, Emil-Ramann-Str. 4, D-85354 Freising-Weihenstephan, Germany. ${ }^{2}$ Institute of Molecular Genetics, Russian Academy of Science, Kurchatov Sq. 2, 123182 Moscow, Russia.

Received: 1 December 2017 Accepted: 30 May 2018

Published online: 08 June 2018

\section{References}

1. Spizizen J. TRANSFORMATION OF BIOCHEMICALLY DEFICIENT STRAINS OF BACILLUS SUBTILIS BY DEOXYRIBONUCLEATE. Proc Natl Acad Sci U S A. 1958; 44:1072-8.

2. Schallmey M, Singh A, Ward OP. Developments in the use of Bacillus species for industrial production. Can J Microbiol. 2004;50:1-17.

3. Liu L, Liu Y, Shin H-D, Chen RR, Wang NS, Li J, et al. Developing Bacillus spp. as a cell factory for production of microbial enzymes and industrially important biochemicals in the context of systems and synthetic biology. Appl Microbiol Biotechnol. 2013;97:6113-27. https://doi.org/10.1007/s00253013-4960-4.
4. Hertel $\mathrm{R}$, Volland $\mathrm{S}$, Liesegang $\mathrm{H}$. Conjugative reporter system for the use in Bacillus licheniformis and closely related Bacilli. Lett Appl Microbiol. 2015;60: 162-7. https://doi.org/10.1111/lam.12352.

5. Schumann W. Production of recombinant proteins in Bacillus subtilis. Adv Appl Microbiol. 2007;62:137-89. https://doi.org/10.1016/S00652164(07)62006-1.

6. Trieu-Cuot P, Carlier C, Martin P, Courvalin P. Plasmid transfer by conjugation from Escherichia coli to gram-positive bacteria. FEMS Microbiol Lett. 1987;48:289-94. https://doi.org/10.1111/j.1574-6968.1987. tb02558.x.

7. Xue G-P, Johnson JS, Dalrymple BP. High osmolarity improves the electrotransformation efficiency of the gram-positive bacteria Bacillus subtilis and Bacillus licheniformis. J Microbiol Methods. 1999;34:183-91. https://doi.org/ 10.1016/S0167-7012(98)00087-6.

8. Kostner D, Rachinger M, Liebl W, Ehrenreich A. Markerless deletion of putative alanine dehydrogenase genes in Bacillus licheniformis using a codBA-based counterselection technique. Microbiology. 2017; https://doi. org/10.1099/mic.0.000544.

9. Pédelacq J-D, Cabantous S, Tran T, Terwilliger TC, Waldo GS. Engineering and characterization of a superfolder green fluorescent protein. Nat Biotechnol. 2006:24:79-88. https://doi.org/10.1038/nbt1172.

10. Figurski DH, Helinski DR. Replication of an origin-containing derivative of plasmid RK2 dependent on a plasmid function provided in trans. Proc Natl Acad Sci U S A. 1979;76:1648-52

11. Ditta G, Stanfield S, Corbin D, Helinski DR. Broad host range DNA cloning system for gram-negative bacteria: construction of a gene bank of Rhizobium meliloti. Proc Natl Acad Sci U S A. 1980;77:7347-51.

12. 1. Ely $B$. Vectors for transposon mutagenesis of non-enteric bacteria. MGG Mol Gen Genet 1985;200:302-304. doi:https://doi.org/10.1007/BF00425440.

13. Schäfer A, Kalinowski J, Simon R, Seep-Feldhaus AH, Pühler A. Highfrequency conjugal plasmid transfer from gram-negative Escherichia coli to various gram-positive coryneform bacteria. J Bacteriol. 1990; 172:1663-6

14. Rachinger $\mathrm{M}$, Bauch $\mathrm{M}$, Strittmatter $\mathrm{A}$, Bongaerts J, Evers S, Maurer $\mathrm{K}-\mathrm{H}$, et al. Size unlimited markerless deletions by a transconjugative plasmid-system in Bacillus licheniformis. J Biotechnol. 2013;167:365-9. https://doi.org/10.1016/j. jbiotec.2013.07.026.

15. Tominaga $Y$, Ohshiro T, Suzuki H. Conjugative plasmid transfer from Escherichia coli is a versatile approach for genetic transformation of thermophilic Bacillus and Geobacillus species. Extremophiles. 2016;20:375-81. https://doi.org/10.1007/s00792-016-0819-9.

16. Espinosa M, del Solar G, Rojo F, Alonso JC. Plasmid rolling circle replication and its control. FEMS Microbiol Lett. 1995;130:111-20. https://doi.org/10. 1111/j.1574-6968.1995.tb07707.x.

17. Lin Y-L, Blaschek HP. Transformation of heat-treated Clostridium acetobutylicum protoplasts with pUB110 plasmid DNA. Appl Environ Microbiol. 1984:48:737-42.

18. Johnson CM, Grossman AD. The composition of the cell envelope affects conjugation in Bacillus subtilis. J Bacteriol. 2016;198:1241-9. https://doi.org/ 10.1128/JB.01044-15.

19. Westers L, Westers H, Quax WJ. Bacillus subtilis as cell factory for pharmaceutical proteins: a biotechnological approach to optimize the host organism. Biochim Biophys Acta. 2004;1694:299-310. https://doi.org/10. 1016/j.bbamcr.2004.02.011

20. Jan J, Valle F, Bolivar F, Merino E. Characterization of the $5^{\prime}$ subtilisin (aprE) regulatory region from Bacillus subtilis. FEMS Microbiol Lett. 2000;183:9-14. https://doi.org/10.1111/j.1574-6968.2000.tb08926.x.

21. Bien TLT, Tsuji S, Tanaka K, Takenaka S, Yoshida K. Secretion of heterologous thermostable cellulases in Bacillus subtilis. J Gen Appl Microbiol. 2014;60: 175-82. https://doi.org/10.2323/jgam.60.175.

22. Ferrari E, Henner DJ, Perego M, Hoch JA. Transcription of Bacillus subtilis subtilisin and expression of subtilisin in sporulation mutants. J Bacteriol. 1988;170:289-95.

23. De Man JC, Rogosa M, Sharpe ME. A medium for the cultivation of lactobacilli. J Appl Bacteriol. 1960;23:130-5. https://doi.org/10.1111/j.13652672.1960.tb00188x

24. Bertani G. Studies on lysogenesis. I. The mode of phage liberation by lysogenic Escherichia coli. J Bacteriol. 1951;62:293-300.

25. Gibson DG, Young L, Chuang R-Y, Venter JC, Hutchison CA, Smith HO. Enzymatic assembly of DNA molecules up to several hundred kilobases. Nat Methods. 2009;6:343-5. https://doi.org/10.1038/nmeth.1318. 
26. Wang W, Malcolm BA. Two-stage PCR protocol allowing introduction of multiple mutations, deletions and insertions using QuikChange site-directed mutagenesis. BioTechniques. 1999;26:680-2.

27. Schanzenbach C, Schmidt FC, Breckner P, Teese MG, Langosch D.

Identifying ionic interactions within a membrane using BLaTM, a genetic

tool to measure homo- and heterotypic transmembrane helix-helix

interactions. Sci Rep. 2017;7:43476. https://doi.org/10.1038/srep43476.

28. Loy A, Schulz C, Lücker S, Schöpfer-Wendels A, Stoecker K, Baranyi C, et al. 165 rRNA gene-based oligonucleotide microarray for environmental monitoring of the betaproteobacterial order "Rhodocyclales". Appl Environ Microbiol. 2005;71: 1373-86. https://doi.org/10.1128/AEM.71.3.1373-1386.2005.

29. Anagnostopoulos C, Spizizen J. Requirements for transformation in Bacillus subtilis. J Bacteriol. 1961;81:741-6.

30. Michna RH, Zhu B, Mäder U, Stülke J. SubtiWiki 2.0-an integrated database for the model organism Bacillus subtilis. Nucleic Acids Res. 2016;44:D654-62. https://doi.org/10.1093/nar/gkv1006.

Ready to submit your research? Choose BMC and benefit from:

- fast, convenient online submission

- thorough peer review by experienced researchers in your field

- rapid publication on acceptance

- support for research data, including large and complex data types

- gold Open Access which fosters wider collaboration and increased citations

- maximum visibility for your research: over $100 \mathrm{M}$ website views per year

At BMC, research is always in progress.

Learn more biomedcentral.com/submissions 